\title{
Comparison of the AdvanSure RV Plus Real-Time RT-PCR and Real-Q RV II Detection Assays for Respiratory Viruses
}

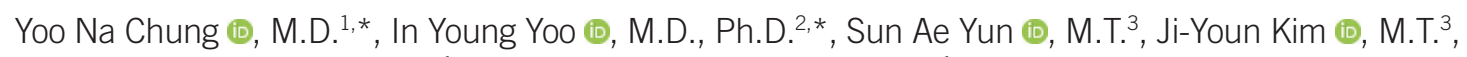
Nam Yong Lee $\mathbb{0}$, M.D., Ph.D. ${ }^{1}$, and Hee Jae Huh (i), M.D., Ph.D. ${ }^{1}$

${ }^{1}$ Department of Laboratory Medicine and Genetics, Samsung Medical Center, Sungkyunkwan University School of Medicine, Seoul, Korea; ${ }^{2}$ Department of Laboratory Medicine, Seoul St. Mary's Hospital, College of Medicine, The Catholic University of Korea, Seoul, Korea; ${ }^{3}$ Center for Clinical Medicine, Samsung Biomedical Research Institute, Samsung Medical Center, Seoul, Korea

\section{Dear Editor,}

Various multiplex molecular assays have been developed and need to be evaluated before use in clinical laboratories. We evaluated the analytical and diagnostic performances of two one-step real-time reverse-transcription PCR assays for detecting respiratory viruses: the AdvanSure RV-plus real-time PCR assay (AdvanSure; LG Chem, Seoul, Korea) and the Real-Q RV II Detection assay (Real-Q RV II; BioSewoom, Seoul, Korea). The AdvanSure assay can simultaneously detect 15 respiratory viruses, including influenza (INF) virus types $A$ and $B$; respiratory syncytial virus types $A$ and $B$; parainfluenza virus (PIV) types 1, 2, and 3; adenovirus (ADV); human metapneumovirus; human bocavirus; coronavirus (CoV) OC43, 229E, and NL63; human rhinovirus (HRV); and enterovirus (ETV) [1]. The Real-Q RV II Detection assay, a revised version of the Real-Q RV Detection assay (BioSewoom) [2, 3], can detect PIV 4 in addition to the viruses detectable by the AdvanSure assay; however, the Real-Q RV II cannot differentiate between CoV 229E and CoV OC43.

We compared the performances of the AdvanSure and RealQ RV II assays for 336 clinical nasopharyngeal swab samples collected from 316 patients with symptoms of respiratory tract infection between January 2016 and May 2018 at Samsung Medical Center, Seoul, Korea. After routine testing, residual samples were stored at $-70^{\circ} \mathrm{C}$ for one to two years prior to analysis. The AdvanSure and Real-Q RV II assays were performed simultaneously. The Institutional Review Board of Samsung Medical Center approved the study (IRB No. SMC 2018-11-064) and waived the requirement for informed consent.

Nucleic acids were extracted from clinical samples using the AdvanSure E3 system (LG Chem) and Nextractor NX-48 (Genosolution Inc., Seoul, Korea) for the AdvanSure and Real-Q RV II assays, respectively, and amplified using the respective assays (i.e. AdvanSure and Real-Q RV II assays), according to the manufacturers' instructions. Positive percent agreement (PPA), negative percent agreement (NPA), and kappa values were used to compare the results of the two assays. Samples with discordant results between the two assays were assessed via uniplex PCR and sequencing in a blind manner with primers identical to those of the AdvanSure and Real-Q RV II assays.

We evaluated the analytical sensitivity of both assays using commercially sourced viral nucleic acids for ADV, INF A, and
Received: August 18, 2020

Revision received: November 21, 2020

Accepted: March 15, 2021

Corresponding author: Hee Jae Huh, M.D., Ph.D.

Department of Laboratory Medicine and Genetics, Samsung Medical Center, Sungkyunkwan University School of Medicine, 81 Irwon-ro, Gangnam-gu, Seoul 06351, Korea

Tel: +82-2-3410-1836, Fax: +82-2-3410-2719, E-mail: pmhhj77@gmail.com

*These authors contributed equally to this study.

\section{(i) (8)}

\section{(C) Korean Society for Laboratory Medicine}

This is an Open Access article distributed under the terms of the Creative Commons Attribution Non-Commercial License (https://creativecommons.org/licenses/by-nc/4.0) which permits unrestricted non-commercial use, distribution, and reproduction in any medium, provided the original work is properly cited. 
PIV 3 (AmpliRun DNA or RNA control; Vircell, Granada, Spain). Ten other microorganisms, including CoV HKU-1, dengue virus serotype 1 , severe acute respiratory syndrome coronavirus 2 , Zika virus, Chlamydophila pneumoniae, Haemophilus influenzae, Legionella pneumophila, Mycobacterium tuberculosis, Mycoplasma pneumoniae, and Streptococcus pneumoniae, were used for analytical specificity evaluation.

Of the 336 samples, 275 (81.8\%) and 264 (78.6\%) were positive for viral infection by the AdvanSure and Real-Q RV II assays, respectively. The PPA, NPA, and kappa values are presented in Table 1. The PPA values for detection of all viruses were $83.3 \%-100 \%$, except for ETV (50\%). NPA values ranged from $97.5 \%$ to $100 \%$. The kappa values ranged from 0.81 to 1.00 , except for ETV (0.42).

Results were discordant for 39 samples. Among these, four samples showed discordant results for two viruses; thus, 43 discordant results were detected in total (Table 2). Using uniplex PCR and sequencing, 77.8\% (21/27) of the discordant AdvanSure-positive and Real-Q RV II-negative results and 62.5\% (10/16) of AdvanSure-negative and Real-Q RV II-positive results were confirmed as positive.

For ADV, IFN A, and PIV 3, the detection limits of the AdvanSure assay were $37.5,5$, and 1 copies $/ \mu \mathrm{L}$, respectively, and those of the Real-Q RV II assay were 37.5, 50, and 500 copies $/ \mu \mathrm{L}$, respectively. In the analytical specificity test, all results were negative, and non-specific positive reactions were not observed in any assay.

Overall, the AdvanSure and Real-Q RV II assays demonstrated equivalent performance for detecting all viral targets. The vast majority of discordant results was associated with high threshold (Ct) values, suggesting low viral genome loads (data not shown). Among a total of eight discordant results for ETV, five were positive only with the AdvanSure assay; of these, none were confirmed to be positive by sequencing, while $80 \%(4 / 5)$ were HRVpositive, suggesting cross-reactivity between HRV and ETV in the AdvanSure assay. Previous studies have demonstrated that the high sequence similarity between HRV and ETV can cause cross-reactivity in molecular assays [4-7]. As we assayed a small number of ETV-positive samples, further studies are needed to confirm our results.

There were eight discrepant results for PIV 3. Notably, all discordant results that were positive only in the AdvanSure assay were confirmed to be positive by sequencing. The lower detection rate of PIV 3 by the Real-Q RV II assay than by the AdvanSure assay might be due to several factors, such as differences in target genes and primers and in the analytical sensitivities of the

Table 1. Detection of respiratory viruses using the AdvanSure RV plus real-time PCR and Real-Q RV II Detection assays

\begin{tabular}{|c|c|c|c|c|c|c|}
\hline \multirow{3}{*}{ Virus } & \multicolumn{4}{|c|}{ Percent agreement* } & \multicolumn{2}{|c|}{ Kappa value } \\
\hline & \multicolumn{2}{|c|}{ Positive } & \multicolumn{2}{|c|}{ Negative } & \multirow{2}{*}{$\begin{array}{c}\text { Observed } \\
\text { kappa value }\end{array}$} & \multirow{2}{*}{$95 \% \mathrm{Cl}$} \\
\hline & $\%(\mathrm{~N})$ & $95 \% \mathrm{Cl}$ & $\%(\mathrm{~N})$ & $95 \% \mathrm{Cl}$ & & \\
\hline ADV & $100(24 / 24)$ & $82.8-100$ & $100(312 / 312)$ & 98.5-100 & 1.00 & \\
\hline INF A & $100(24 / 24)$ & $82.8-100$ & $99.7(311 / 312)$ & 97.9-100 & 0.98 & $0.94-1.00$ \\
\hline INF B & $100(12 / 12)$ & $69.9-100$ & $100(324 / 324)$ & $98.5-100$ & 1.00 & \\
\hline PIV 1 & $100(15 / 15)$ & 74.7-100 & $100(321 / 321)$ & 98.5-100 & 1.00 & \\
\hline PIV 2 & $100(15 / 15)$ & $74.7-100$ & $100(321 / 321)$ & $98.5-100$ & 1.00 & \\
\hline PIV 3 & $100(18 / 18)$ & $78.1-100$ & $97.5(310 / 318)$ & 94.9-98.8 & 0.81 & $0.68-0.94$ \\
\hline HRV & $84.4(38 / 45)$ & $69.9-93.0$ & $99(288 / 291)$ & $96.8-99.7$ & 0.87 & $0.79-0.95$ \\
\hline RSV A & $83.3(15 / 18)$ & $57.7-95.6$ & $100(318 / 318)$ & $98.5-100$ & 0.90 & $0.80-1.00$ \\
\hline RSV B & $100(23 / 23)$ & $82.2-100$ & $100(313 / 313)$ & $98.5-100$ & 1.00 & \\
\hline HMPV & $92.9(26 / 28)$ & $75.0-98.8$ & $99.7(307 / 308)$ & 97.9-100 & 0.94 & $0.87-1.00$ \\
\hline CoV 229E/OC43 & $100(28 / 28)$ & $85.0-100$ & $98.4(303 / 308)$ & $96.0-99.4$ & 0.91 & $0.83-0.99$ \\
\hline CoV NL63 & $100(13 / 13)$ & 71.7-100 & $99.4(321 / 323)$ & $97.5-99.9$ & 0.93 & $0.82-1.00$ \\
\hline BoV & $93.8(15 / 16)$ & $67.7-99.7$ & $99.4(318 / 320)$ & $97.5-99.9$ & 0.90 & $0.80-1.00$ \\
\hline ETV & $50(3 / 6)$ & $13.9-86.1$ & $98.5(325 / 330)$ & $96.3-99.4$ & 0.42 & $0.09-0.75$ \\
\hline
\end{tabular}

*The Real-Q RV II assay was used as the comparative assay to calculate the positive percent agreement and negative percent agreement. Abbreviations: ADV, adenovirus; INF A, influenza A virus; INF B, influenza B virus; PIV 1- 3, parainfluenza virus types 1 to 3; HRV, human rhinovirus; RSV A, respiratory syncytial virus A; RSV B, respiratory syncytial virus B; HMPV, human metapneumovirus; CoV, coronavirus; BoV, bocavirus; ETV, enterovirus. 
Table 2. Analysis of positive results obtained with the AdvanSure RV plus real-time PCR and Real-Q RV II Detection assays ( $N=312)$

\begin{tabular}{|c|c|c|c|c|c|c|}
\hline \multirow[b]{2}{*}{ Virus } & \multirow{2}{*}{\multicolumn{2}{|c|}{$\begin{array}{l}\text { AdvanSure + I } \\
\text { Real-Q RV II + }\end{array}$}} & \multicolumn{2}{|c|}{ AdvanSure + /Real-Q RV II - } & \multicolumn{2}{|c|}{ AdvanSure - /Real-Q RV II + } \\
\hline & & & Samples (N) & $\begin{array}{l}\text { Positive results in uniplex } \\
\text { PCR and sequencing (N) }\end{array}$ & Samples (N) & $\begin{array}{l}\text { Positive results in uniplex } \\
\text { PCR and sequencing (N) }\end{array}$ \\
\hline ADV & 24 & & 0 & 0 & 0 & 0 \\
\hline INF A & 24 & & 1 & 1 & 0 & 0 \\
\hline INF B & 12 & & 0 & 0 & 0 & 0 \\
\hline PIV 1 & 15 & & 0 & 0 & 0 & 0 \\
\hline PIV 2 & 15 & & 0 & 0 & 0 & 0 \\
\hline PIV 3 & 18 & & 8 & 8 & 0 & 0 \\
\hline HRV & 38 & & 3 & 3 & 7 & 6 \\
\hline RSV A & 15 & & 0 & 0 & $3^{*}$ & 0 \\
\hline RSV B & 23 & & 0 & 0 & 0 & 0 \\
\hline HMPV & 26 & & 1 & 1 & 2 & 2 \\
\hline CoV 229E/0C43 & 28 & & 5 & $4^{\dagger}$ & 0 & 0 \\
\hline CoV NL63 & 13 & & 2 & 2 & 0 & 0 \\
\hline BoV & 15 & & 2 & 2 & 1 & 1 \\
\hline ETV & 3 & & $5^{*}$ & 0 & $3^{*}$ & 1 \\
\hline
\end{tabular}

${ }^{*}$ One of these cases could not be confirmed by sequencing due to lack of residual samples; ${ }^{\dagger}$ These cases were confirmed as having CoV OC43 infection. Abbreviations: AdvanSure, AdvanSure RV plus real-time PCR; Real-Q RV II, Real-Q RV II Detection assay; ADV, adenovirus; INF A, influenza A virus; INF B, influenza B virus; PIV 1-3, parainfluenza virus type 1 to 3; HRV, human rhinovirus; RSV A, respiratory syncytial virus A; RSV B, respiratory syncytial virus B; HMPV, human metapneumovirus; CoV, coronavirus; BoV, bocavirus; ETV, enterovirus.

assays $[8,9]$. Thus, we conclude that the analytical sensitivity of the Real-Q RV II assay for PIV 3 is lower than that of the AdvanSure assay.

To the best of our knowledge, this is the first study comparing the performances of the AdvanSure and Real-Q RV II assays. Despite some discordant results, these assays yielded comparable results and were found to be potentially useful tools in clinical laboratories. Further studies with a large number of positive samples need to be performed in future.

\section{ACKNOWLEDGEMENT}

None.

\section{AUTHOR CONTRIBUTION}

Lee NY and Huh HJ initiated and designed the study and coordinated the drafting of the manuscript. Yun SA and Kim JY participated in sample collection and experiments. Chung YN and Yoo IY carried out data analysis and wrote the manuscript. Lee NY and Huh HJ supervised the study and reviewed the manuscript. All authors read and approved the final manuscript.

\section{CONFLICTS OF INTEREST}

The authors declare that there is no conflict of interest regarding publication of this article.

\section{RESEARCH FUNDING}

This study was supported by LG Chem, Korea. The sponsor was not involved in study design, data interpretation, or manuscript preparation.

\section{ORCID}

Yoo Na Chung In Young Yoo Sun Ae Yun Ji-Youn Kim Nam Yong Lee Hee Jae Huh https://orcid.org/0000-0002-4164-6583 https://orcid.org/0000-0003-1505-846X https://orcid.org/0000-0002-8104-3496 https://orcid.org/0000-0002-9206-7338 https://orcid.org/0000-0003-3688-0145 https://orcid.org/0000-0001-8999-7561 


\section{REFERENCES}

1. Uwizeyimana JD KM, Kim D, Byun J, Yong D. Comparison of multiplex real-time polymerase chain reaction assays for detection of respiratory viruses in nasopharyngeal specimens. Ann Clin Microbiol 2019;22:3541.

2. Lee E, Shin S, Kim M, Lee YK, Kang HJ, Kim HS, et al. Evaluation of the real-Q RV detection kit for the identification of viruses that result in respiratory infections. Lab Med Online 2019;9:17-21.

3. Yun SG, Kim MY, Choi JM, Lee CK, Lim CS, Cho Y, et al. Comparison of three multiplex PCR assays for detection of respiratory viruses: Anyplex II RV16, AdvanSure RV, and Real-Q RV. J Clin Lab Anal 2018;32: e22230.

4. Shibib DR, Matushek SM, Beavis KG, Gawel SH, Charnot-Katsikas A. BioFire FilmArray respiratory panel for detection of enterovirus D68. J Clin Microbiol 2016;54:457-9.

5. McAllister SC, Schleiss MR, Arbefeville S, Steiner ME, Hanson RS, Pollock C, et al. Epidemic 2014 enterovirus D68 cross-reacts with human rhinovirus on a respiratory molecular diagnostic platform. PLoS One 2015; 10:e0118529.

6. Dabisch-Ruthe M, Vollmer T, Adams O, Knabbe C, Dreier J. Comparison of three multiplex PCR assays for the detection of respiratory viral infections: evaluation of XTAG respiratory virus panel fast assay, RespiFinder 19 assay and RespiFinder SMART 22 assay. BMC Infect Dis 2012;12:163.

7. Gharabaghi F, Hawan A, Drews SJ, Richardson SE. Evaluation of multiple commercial molecular and conventional diagnostic assays for the detection of respiratory viruses in children. Clin Microbiol Infect 2011; 17:1900-6.

8. Ko DH, Kim HS, Hyun J, Kim HS, Kim JS, Park KU, et al. Comparison of the Luminex XTAG Respiratory Viral Panel Fast v2 Assay With Anyplex II RV16 Detection Kit and AdvanSure RV Real-Time RT-PCR Assay for the detection of respiratory viruses. Ann Lab Med 2017;37:408-14.

9. Gadsby NJ, Hardie A, Claas EC, Templeton KE. Comparison of the Luminex Respiratory Virus Panel fast assay with in-house real-time PCR for respiratory viral infection diagnosis. J Clin Microbiol 2010;48:22136. 